\title{
Analysis on conversion process from paper record ECG to computer based ECG
}

\begin{abstract}
The capacity of electrocardiograms (ECG) recorded in hospital is increasing. Although modern electrocardiographs have digital output, most of ECG's are still recorded on grid papers. Recently, exchanging patients' clinical information between healthcare facilities has become very important. It will be very helpful if paper type of ECG could be converted to digital form. In this study, a morphological method is developed to digitize ECG signal from the paper charts. The results show that the method can erase the background noise and provide the digital ECG signal from ECG paper charts correctly. ECG signal digitization is practically used in ECG data exchanging between healthcare providers. Experimental results on sample ECG paper records are very encouraging and show the promise of efficiency in ECG data storage and retrieval and easy manipulation for clinical uses.
\end{abstract}

Keywords: paper record ECG, computer-based ECG, conversion techniques, image processing, biomedical signal processing
Volume I Issue 2 - 2017

\author{
Hla Myo Tun,' Win Khaing Moe, ${ }^{2}$ Zaw Min \\ Naing ${ }^{2}$ \\ 'Department of Electronic Engineering, Yangon Technological \\ University, Myanmar \\ ${ }^{2}$ Department of Research and Innovation, Myanmar
}

\begin{abstract}
Correspondence: Hla Myo Tun, Department of Electronic Engineering, Yangon Technological University, Myanmar,
\end{abstract} Email hmyotun@gmail.com

Received: September II, 2017 | Published: September 22, 2017

\section{Introduction}

An ECG is simply a representation of the electrical activity of the heart muscle as it changes with time, usually printed on paper for easier analysis. Like other muscles, cardiac muscle contracts in response to electrical depolarization of the muscle cells. The sum of this electrical activity is amplified and recorded for just a few seconds that know as an ECG. The electrocardiogram (ECG) represents a graph of variation in electrical potential generated by the heart and recorded at the body surface. Recently, exchanging patients' clinical information between healthcare facilities has become very important. Measurements of parameters from electrocardiograms (ECGs) are still largely performed from paper ECG records. It will be very helpful, if plane paper type of ECG could be converted to digital form. At the same time, the new requirements justify the need for tools to convert existing paper ECG records into digital format, particularly for retrospective studies. A computer application was developed for the conversion of paper ECG records to digital ECG files. ${ }^{1-6}$ In general, the background of ECG paper charts can be divided into three types: uniform background, background with colored grid and background with black grid. Electrocardiogram (ECG) signals are usually recorded onto standard grid papers in hospitals as a routine clinical examination for diagnosis of possible cardiac failure. There is a need to convert the existing ECG paper records into electronic forms for efficient retrieval for clinical uses.

It is to be noted that printed ECG reports include some characters as well as annotations while taking an image of such ECG strips. It is desirable to remove these printed characters. Efficient noise removal and image enhancing algorithms are also required so as to increase overall digitization process accuracy. ${ }^{7-10}$ This research work proposes an effective algorithm for extracting the digitized signal from ECG paper strips. A system prototype is designed to convert ECG paper records into electronic ECG recording forms so that they can be either efficiently retrieved as needed, or analyzed by ECG signal processing algorithms, or transmitted through computer networks for clinical purposes. In the research, the scanned binary images of ECG paper records are analyzed using image processing techniques, such as filtering and morphological procedures. The direction of digitizing the ECG paper records is referred in which morphological approach is used to remove the background grid and isolated pixels such as characters from the paper recorded ECG.

\section{System description}

The ECG charts were scanned into images using a commercial A4 scanner with 600dpi gray scale settings. Before the operation, a region of interest is being defined that will help in reducing the processing time and much more it will allow a specific selection of a particular part of the waveform (Figure 1). The algorithm starts with reading an image and converts it from gray scale to binary image in order to prepare it for the binary morphological operation. A threshold is applied with image to binary conversion then the segments that are less than a specified number of pixels can be removed. The binary image is processed with a particular neighborhood morphological binary operation that will estimate the background of the image that will be subtracted from the selected image. The result image contains residual effects from the subtraction of the background. To reduce these effects, region based segmentation is applied. Then, the segments that represent the ECG wave and background are separated. Region based segmentation is applied for more isolated pixels that represent printed characters or noise reduction..$^{8-12}$ The final image will contain the waveform with minimal effect on the boundary. The next step is to smooth the boundary of the ECG wave with a binary morphological thicken. The final step is to convert the waveform in the final processed image to $1 \mathrm{D}$ signal that can be then manipulated for any further signal processing. This process is shown in the block diagram of (Figure 1). 


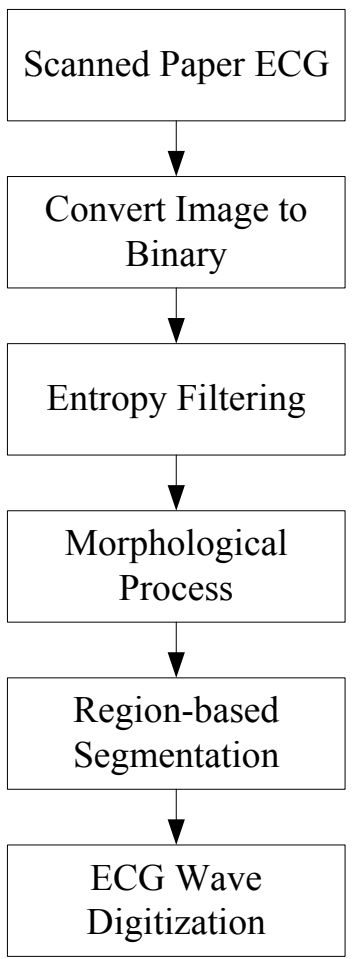

Figure I Conversion of ECG from Paper Record to Computer-based ECG.

\section{Paper recorded ECG signal digitization algo-} rithm

\section{Digitization algorithm}

ECG strips (printed on a thermal paper) are scanned and scanned images are enhanced for the signal lines sharper. The grid is removed from the scanned ECG images by using threshold and morphological operation. Region based segmentation is applied for removing isolated pixels that represent printed characters or noise. ${ }^{13-15}$ Final processed ECG signal is obtained by interpolating the pixel values and the signal is represented by a specific signal pixel per column. The overall algorithmic steps are shown in Figure 2.

\section{Digitization process}

There are three main sections in ECG signal digitization process. They are as follow:
i. Background removal,
ii. Characters and small object removal,
iii. Conversion from waveform to 1-D signal.

\section{Background removal}

The following steps are implemented for the background grip removal.
i. Scan into images using a commercial A4 scanner with 600dp gray scale settings
ii. Start with reading an image.
iii. Enhance Image.

iv. Convert it from gray scale to binary image by applying a threshold level to remove the pixels that are less than a threshold value.

v. Process with a particular neighborhood morphological binary operation that will estimate the background of the image.

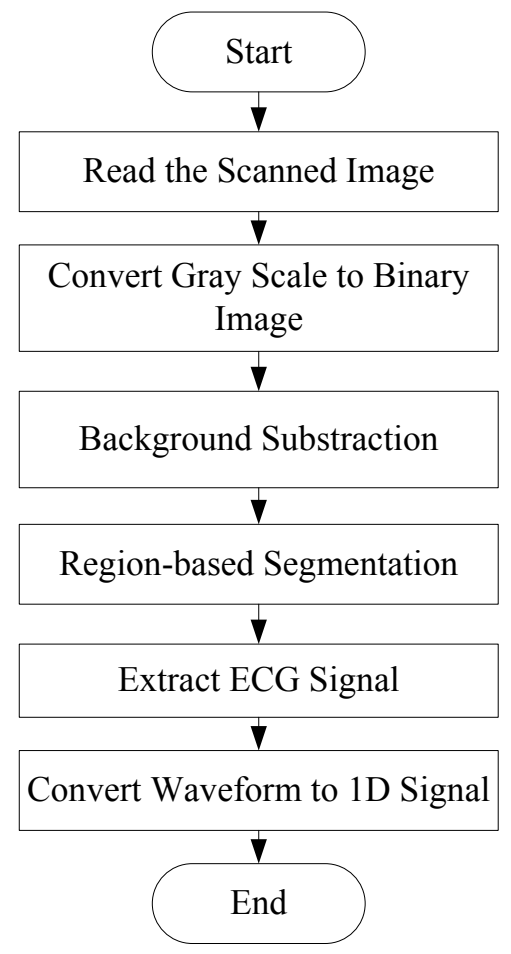

Figure 2 Flowchart of ECG Paper Record Digitization Process.

\section{Scanning and standardization}

Based on the resolution of scanning and paper speed, the pixel is defined in terms of time and amplitude units. For example, a resolution of 600dpi implies 600pixels in an inch $(25.4 \mathrm{~mm})$. Thus the number of pixels per $\mathrm{mm}$ can be calculated. Paper speed of $25 \mathrm{~mm} / \mathrm{sec}$ i.e. 1 $\mathrm{sec}=25 \mathrm{~mm}$ and calibration mark of $1 \mathrm{mV}$ amplitude $=10 \mathrm{~mm}$ is used to evaluate the value of each pixel in the time scale and amplitude scale. Pixel value in time scale is found to be $1.693 \mathrm{~ms}$ and amplitude scale to be $4.233 \mathrm{mV}$. These values are used during the digital time series signal generation.

\section{Load image and enhancement}

This step enhances the ECG image by making the signal lines sharper. Im adjust command is applied for making background noise lighter than the main ECG signal. $\mathrm{J}=$ im adjust (I) maps the intensity values in grayscale image I to new values in J such that $1 \%$ of data is saturated at low and high intensities of I. This increases the contrast of the output image $J$ and adjusts image intensity values.

\section{Convert gray scale to binary image based on threshold}

This is followed by setting a threshold. Threshold value is chosen by comparing between noise pixels and pixels representing actual ECG signal. If ECG signal pixels values close to the threshold then pixels will be made darker by subtracting a fix value. The noise pixels values that close to the threshold value will be made lighter by adding a fix value. Therefore, the resulting image will contain 
distinct ECG signal in the image. $\mathrm{BW}=\mathrm{im} 2 \mathrm{bw}$ (I, level) converts the grayscale image I to a binary image. The output image BW replaces all pixels in the input image with luminance greater than level with the value 1 (white) and replaces all other pixels with the value 0 (black). Specify level in the range $[0,1]$. This range is relative to the signal levels possible for the image's class. Therefore, a level value of 0.5 is midway between black and white, regardless of class. To compute the level argument, the function "gray thresh" can be used. If level is not specified, im 2 bw uses the value 0.5 .

\section{Characters and small object removal}

After removing the background grip, the isolated pixels such as characters are still exist. To remove these small objects the following steps are applied

i. Local entropy of grayscale image,

ii. Morphologically open binary image (remove small objects),

iii. Region based segmentation to remove the isolated characters,

iv. Remove the segments that are less than a specified number of pixels,

v. Subtract the ECG signal only (Remove characters),

vi. Smooth the ECG signal by morphological thicken process because of containing residual effects from the subtraction of the background.

\section{Local entropy of grayscale image}

$\mathrm{J}=$ entropyfilt (I) returns the array $\mathrm{J}$, where each output pixel contains the entropy value of the 9-by-9 neighborhood around the corresponding pixel in the input image I. "I" can have any dimension. If "I" has more than two dimensions, entropyfilt treats it as a multidimensional grayscale image and not as a true color (RGB) image. The output image $\mathrm{J}$ is the same size as the input image I. For pixels on the borders of I, entropyfilt uses symmetric padding. In symmetric padding, the values of padding pixels are a mirror reflection of the border pixels in
I. J=entropyfilt (I, NHOOD) performs entropy filtering of the input image I where specify the neighborhood in NHOOD. NHOOD is a multidimensional array of zeros and ones where the nonzero elements specify the neighbors. NHOOD's size must be odd in each dimension. By default, entropyfilt uses the neighborhood true (9). Entropyfilt determines the center element of the neighborhood by floor ((size $(\mathrm{NHOOD})+1) / 2$ ). The entropyfilt functions operate by defining a neighborhood around the pixel of interest and calculating the statistic for the neighborhood to determine the pixel value in the output image. The entropyfilt function calculates the entropy of the neighborhood and assigns that value to the output pixel. Note that, by default, the entropyfilt function defines a 9-by-9 neighborhood around the pixel of interest. To calculate the entropy of an entire image, use the following entropy function.

$$
\text { Entropy }=-\operatorname{sum}\left(\mathrm{p}_{\mathrm{i}}{ }^{*} \log _{2} \mathrm{p}_{\mathrm{i}}\right)
$$

Where $p_{i}$ is the probability that the difference between 2 adjacent pixels is equal to $i$, and $\log _{2}$ is the base 2 logarithm.

In the above (Figure 3), the entropy value for the centre pixel " 0 " can be calculated as follow:

Probability of $1=3 / 9$

Probability of $0=6 / 9$

Entropy value for "0" $=-\Sigma\left[\left(\frac{3}{9} \log _{2} \frac{3}{9}\right)+\left(\frac{6}{9} \log _{2} \frac{6}{9}\right)\right]=0$. 0.918295

For pixels on the borders of Image, entropyfilt uses symmetric padding. Therefore, the entropy value for the last pixel " 0 " in the above (Figure 4) can be calculated as follow. Take the four pixel value in the previous of "0" as a mirror reflection.

001000100

Probability of $1=2 / 9$

Probability of $0=7 / 9$

$$
\text { Entropy value for "0" that has last position }=-\Sigma\left[\left(\frac{2}{9} \log _{2} \frac{2}{9}\right)+\left(\frac{7}{9} \log _{2} \frac{7}{9}\right)\right]=0.7642
$$

The entropy value for the third pixel " 0 " in the above (Figure 5) can be calculated as follow. Take the interested pixel " 0 " as center and then fill the blank position of pixel as a mirror reflection.

\section{1}

Probability of $1=4 / 9$

Probability of $0=5 / 9$

$$
\text { Entropy value for " } 0 \text { " that has third position }=-\Sigma\left[\left(\frac{4}{9} \log _{2} \frac{4}{9}\right)+\left(\frac{5}{9} \log _{2} \frac{5}{9}\right)\right]=0.991076
$$

The entropy value for the other pixels can be calculated by using entropy function as described above.

\section{Converts the matrix to the intensity image}

$\mathrm{I}=$ mat2gray $(\mathrm{A},[\operatorname{amin} \operatorname{amax}])$ converts the matrix A to the intensity image I. The returned matrix I contains values in the range 0.0 (black) to 1.0 (full intensity or white). The amin and amax are the values in $\mathrm{A}$ that correspond to 0.0 and $1.0 \mathrm{in} \mathrm{I}$.

$\mathrm{I}=$ mat2gray (A) sets the values of amin and amax to the minimum and maximum values in A. The input array A can be logical or numeric. The output image "I" is double.

\section{Morphologically open binary image}

$\mathrm{BW} 2=\mathrm{bw}$ are a open $(\mathrm{BW}, \mathrm{P})$ removes from a binary image all connected components (objects) that have fewer than $\mathrm{P}$ pixels, producing another binary image, BW2. The default connectivity is 8 for two dimensions, 26 for three dimensions, and conndef (ndims (BW), 'maximal') for higher dimensions. In this research work, "bwareopen" is used for removing the isolated characters that pixels are connected continuously. 


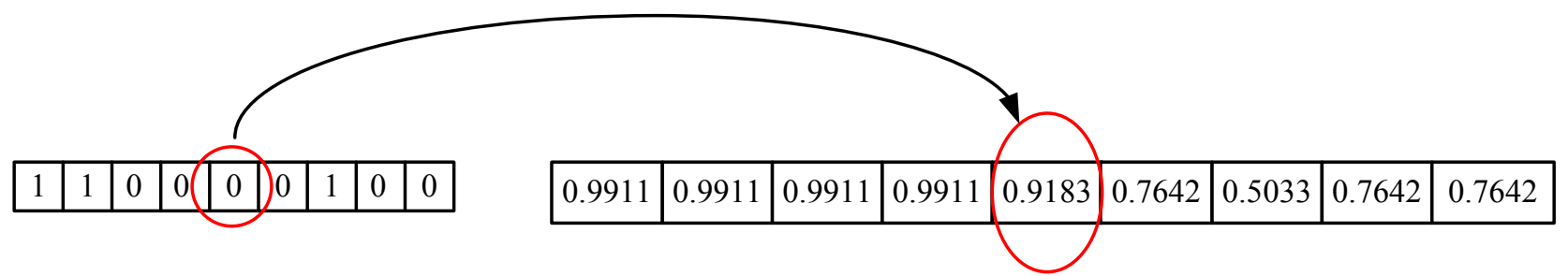

Figure 3 Determining Pixel Values in Entropy Filtered Output Image (I).

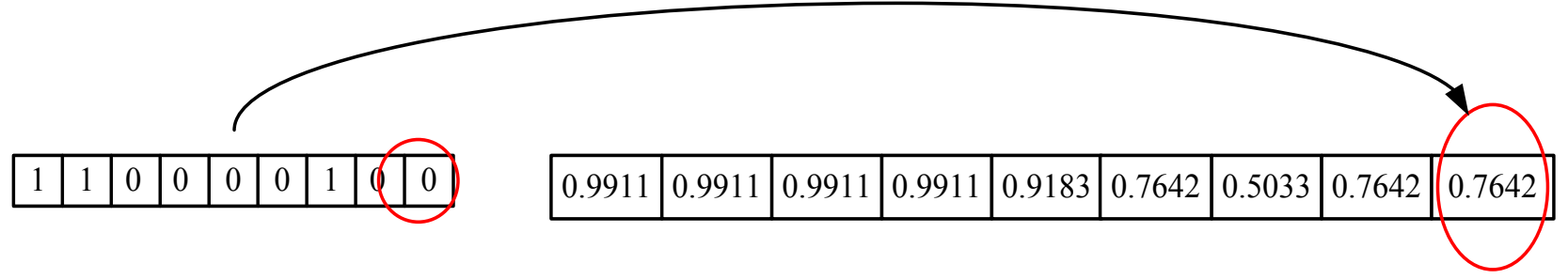

Figure 4 Determining Pixel Values in Entropy Filtered Output Image (2).

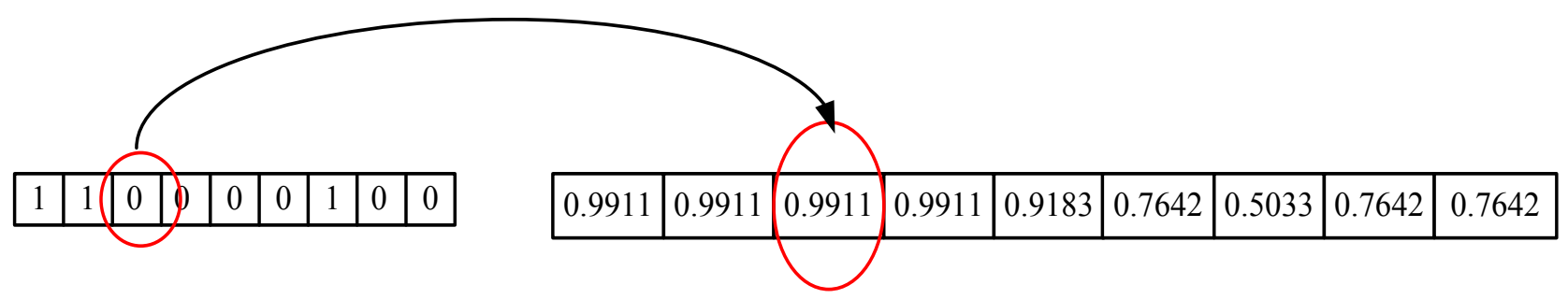

Figure 5 Determining Pixel Values in Entropy Filtered Output Image (3).

\section{Region based segmentation}

This step removes the isolated pixels that do not represent the signal (printed characters). This step comprises of the following steps:-

Step 0: Remove the frame of the image that is border of the input image.

Step 1: Scan the input ECG image column by column.

Step 2: Extract the black pixels (pixels that represent the signal).

Step 3: In case of the presence of isolated pixels, create one segment with them.

Step 4: Place each segment on the original input image

Step 5: Show the boundary of the each segment

Step 6: Subtract the segment that represents the ECG signal from the other segment.

\section{Smoothing the ECG signal}

ECG signal is smoothed by morphological thicken process because of containing residual effects from the subtraction of the background. Morphological operation "thicken" is used to remove the pixels that exist on the boundary of the signal.

$\mathrm{BW} 2=\mathrm{bwm}$ or $\mathrm{ph}(\mathrm{BW}$, operation $)$ applies a specific morphological operation to the binary image BW. With $\mathrm{n}=$ Inf, thicken objects by adding pixels to the exterior of objects until doing so would result in previously unconnected objects being 8-connected.

\section{Conversion from waveform image to I-D signal}

Final step of digitization is axis value identification. The following section discusses axis identification system.

\section{Axis identification}

Several different types of data plotting were analyzed for the sake of the generality of the methodology proposed herein. The piece of paper used to register the data may contain a grid, a box, one horizontal line and one vertical line, or no axis, but in each case a specific analysis needs to be performed in order to adequately interpret the value of the signal obtained, compensating offsets, etc. There are many methods on axis identification. The most complex and difficult part of the proposed algorithm is the axis identification stage. But the easiest way to identify the axis value is the calculation based on the height and width of input image. In this work, the $\mathrm{x}$ and $y$ axis values are calculated based on the input scanned image. ECG scanned paper speed is $25 \mathrm{~mm} / \mathrm{sec}$. Therefore $1 \mathrm{sec}=25 \mathrm{~mm}$ and calibration mark of $1 \mathrm{mV}$ amplitude $=10 \mathrm{~mm}$. If the input ECG image is $100 \mathrm{~mm}$ width and $40 \mathrm{~mm}$ high, then the time scale on $\mathrm{x}$ axis must be 4 $\mathrm{sec}$ and the amplitude scale on y axis must be $4 \mathrm{mV}$. The disadvantage of this method is that the calculation of the axis values depends on input image size.

\section{Simulation results}

Firstly load scanned ECG signal image (.jpg, .bmp). ECG paper recordings need to be scanned. Scanning resolution can be $600 / 300 / 200$ dpi (dots per inch). In this work the image is obtained 
by scanning with 600dpi resolution. The image from (Figures 6-21) import the scanned image of the recording as the JPEG file. (Figure 6) is $600 \mathrm{dpi}$ resolutions. The algorithm uses the function im read ( ) to represents a scanned ECG paper recording.

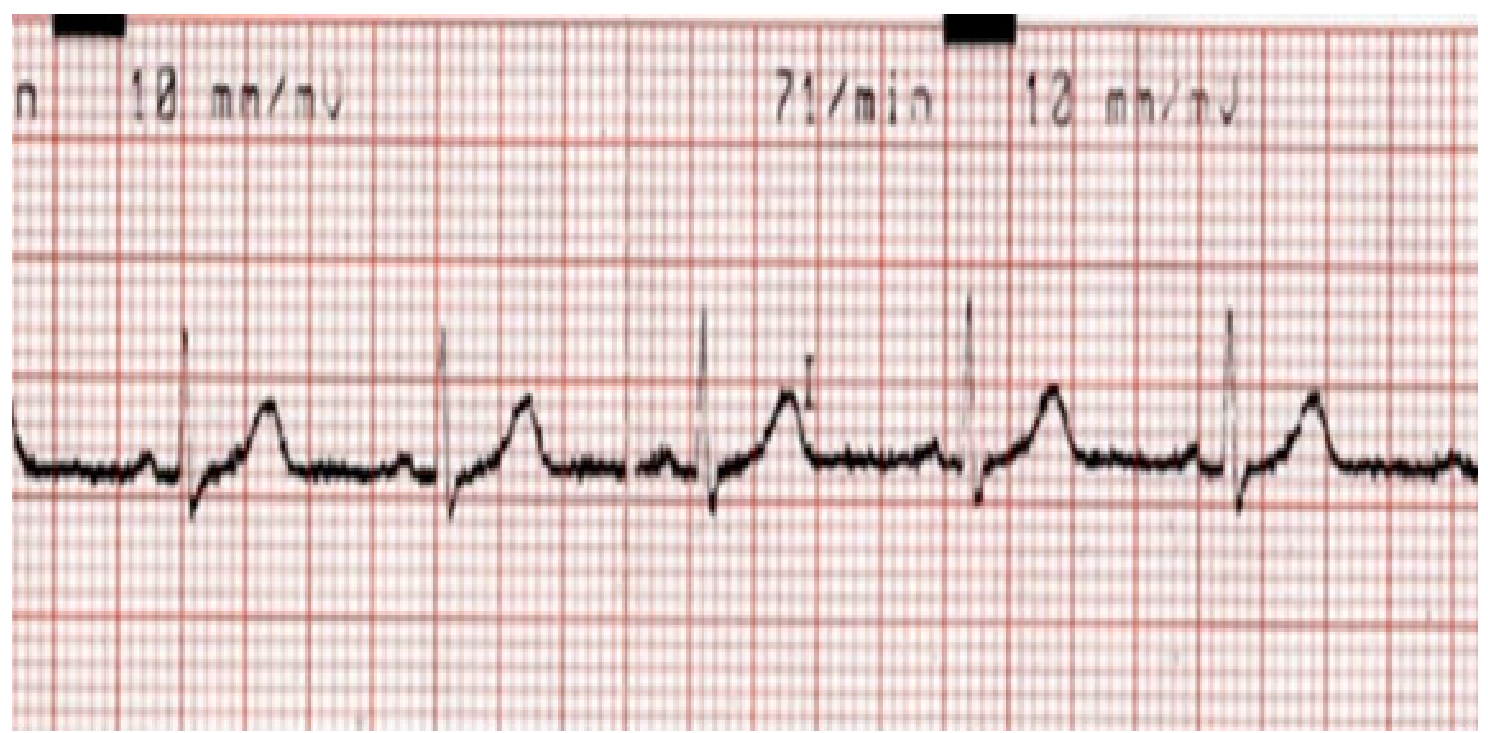

Figure 6 A Scanned ECG Paper.

\section{Enhancement Image}

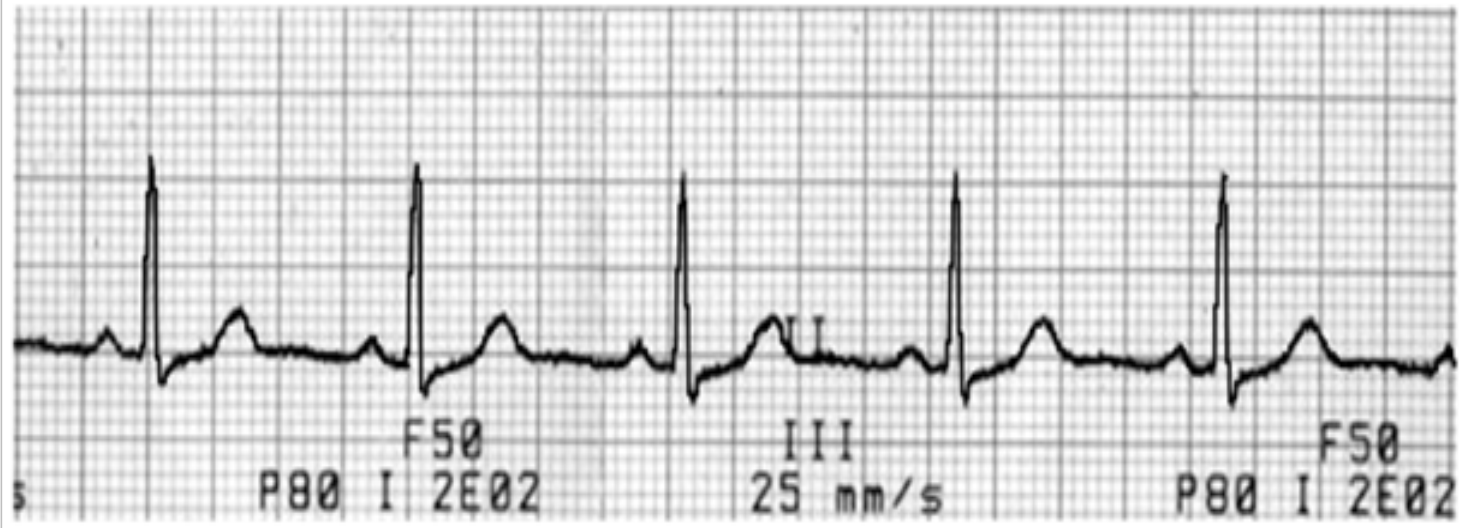

Figure 7 Enhanced Imaged.

\section{Background Remove}

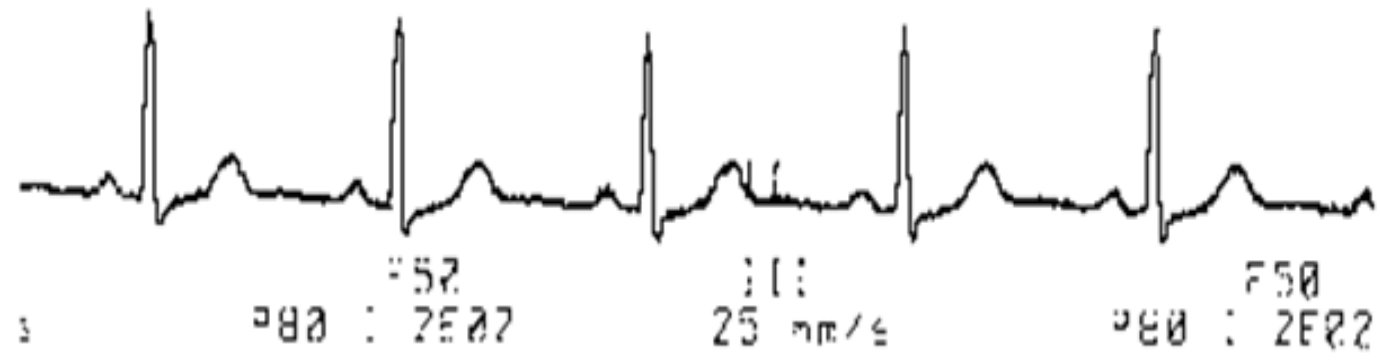

Figure 8 Background Removed Image. 
Bwareaopen

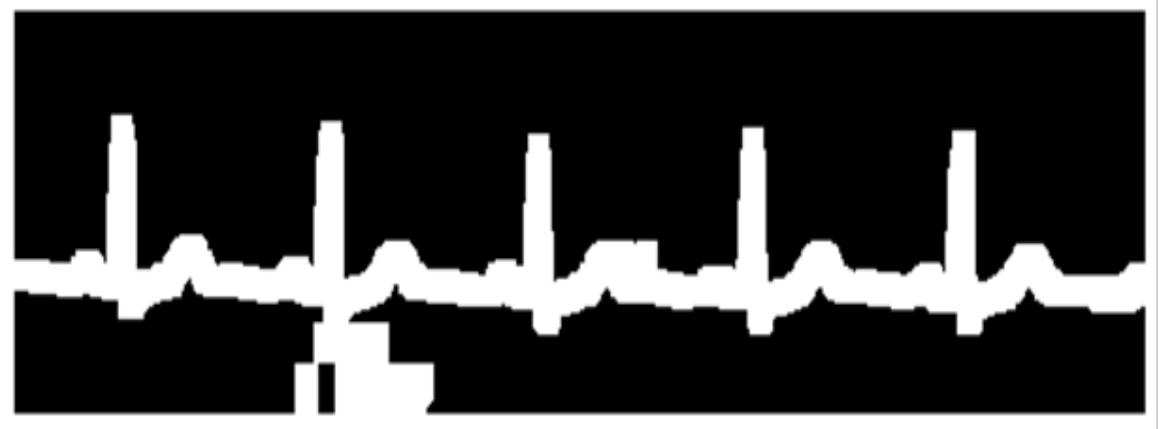

Figure 9 Morphologically area Opened Image.

Segment1

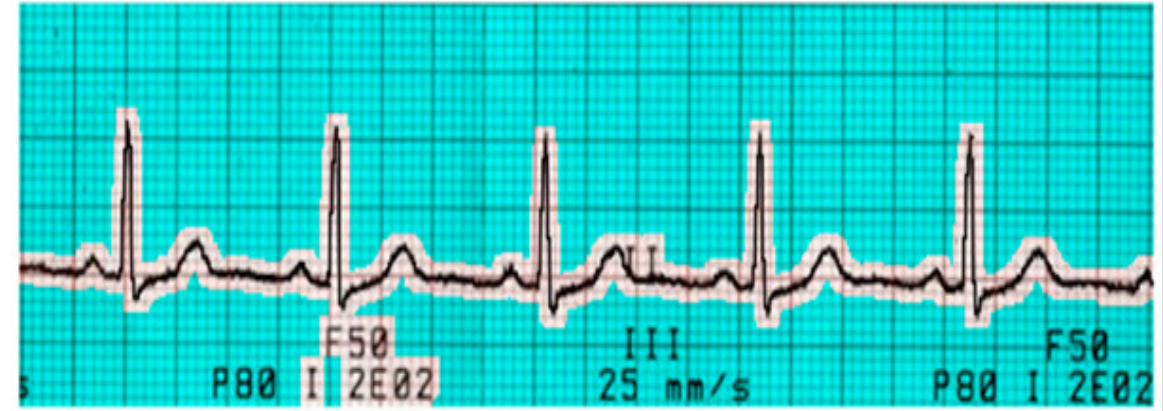

Figure 10 Background Segment I.

Segment2

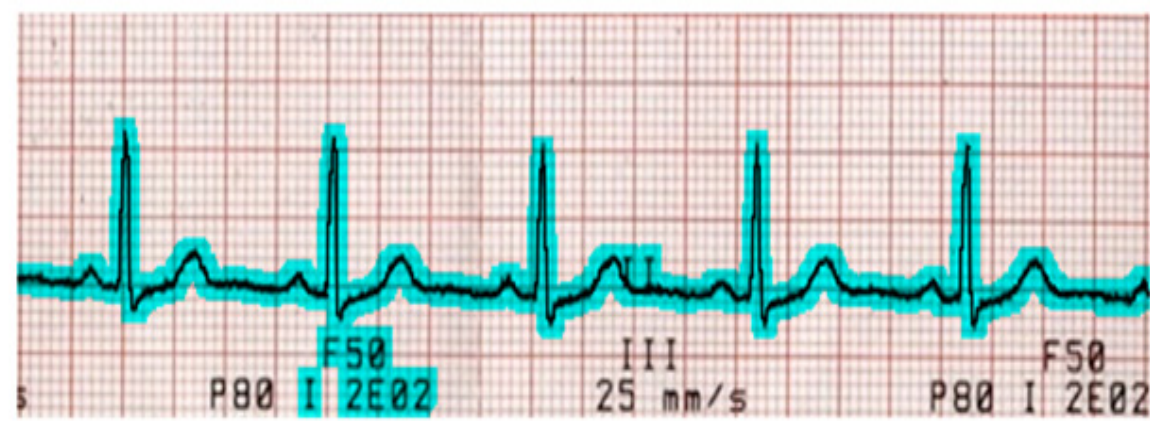

Figure II Signal Segment 2.

Segment Subtraction

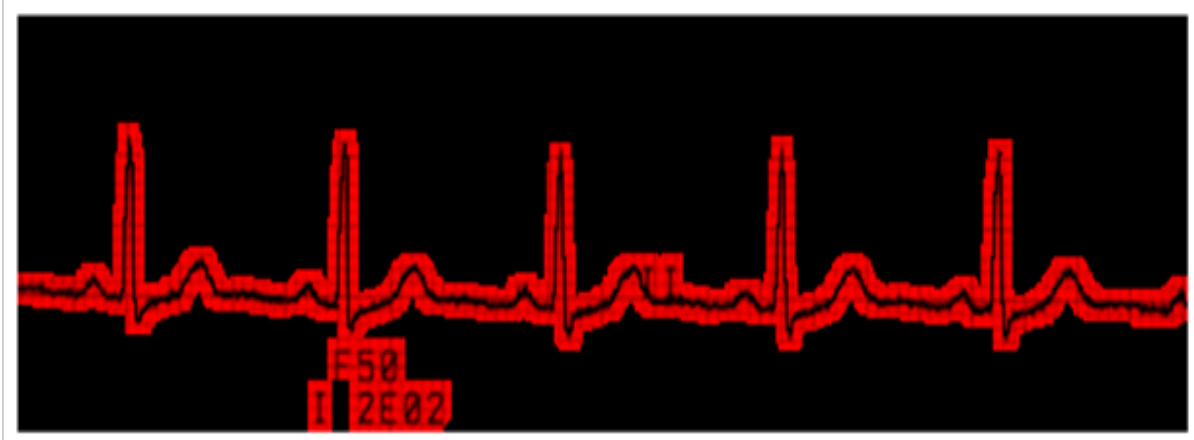

Figure 12 Subtraction of Segment I and 2.

Citation: Tun HM, Moe WK, Naing ZM. Analysis on conversion process from paper record ECG to computer based ECG. MOJ App Bio Biomech. 20I7; I (2):69-8I. DOI: 10.15406/mojabb.2017.01.000I I 
Substraction

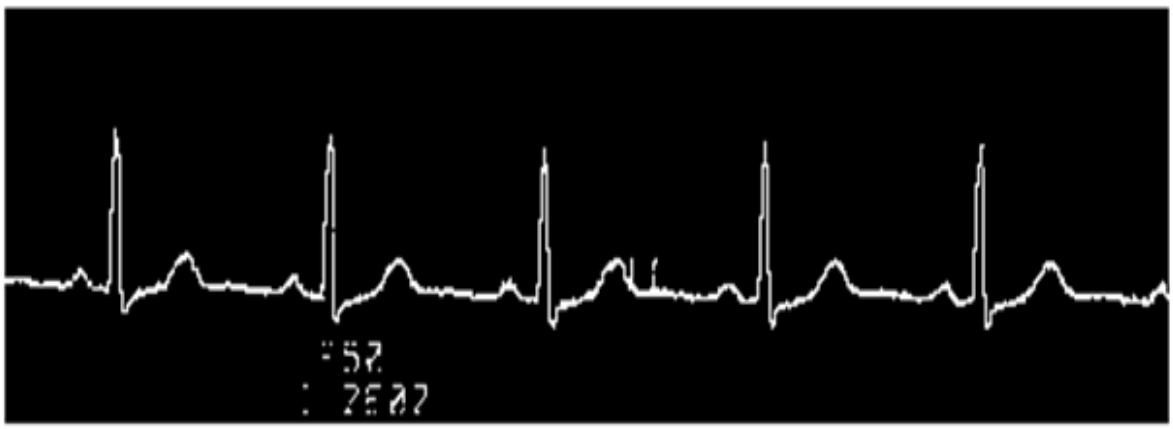

Figure 13 ECG Signal.

Digital ECG Signal

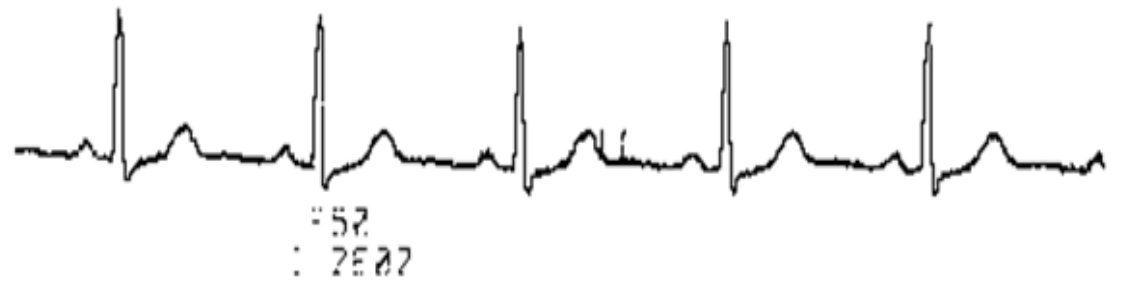

Figure 14 Digital ECG Signal.

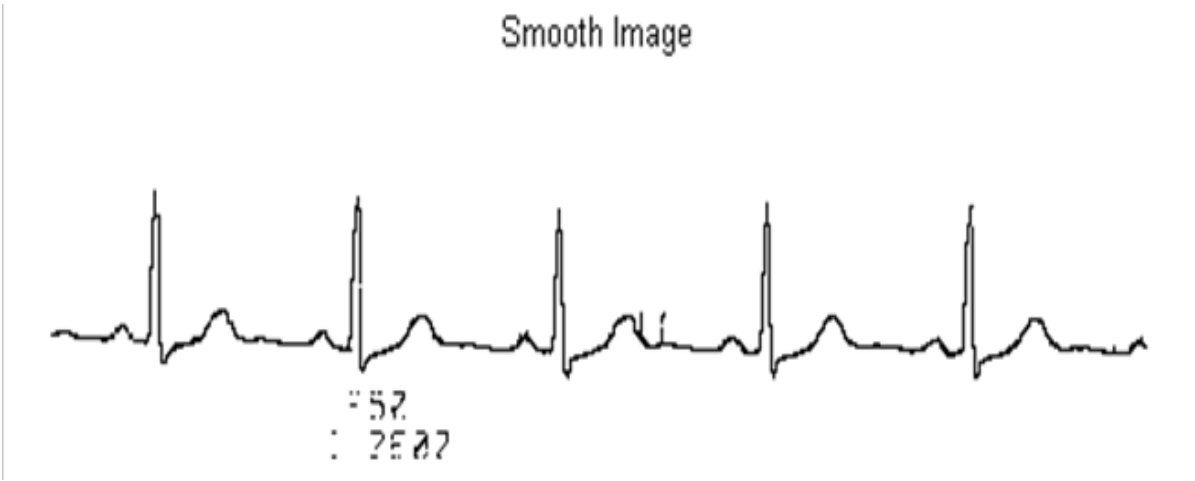

Figure 15 ECG Signal.

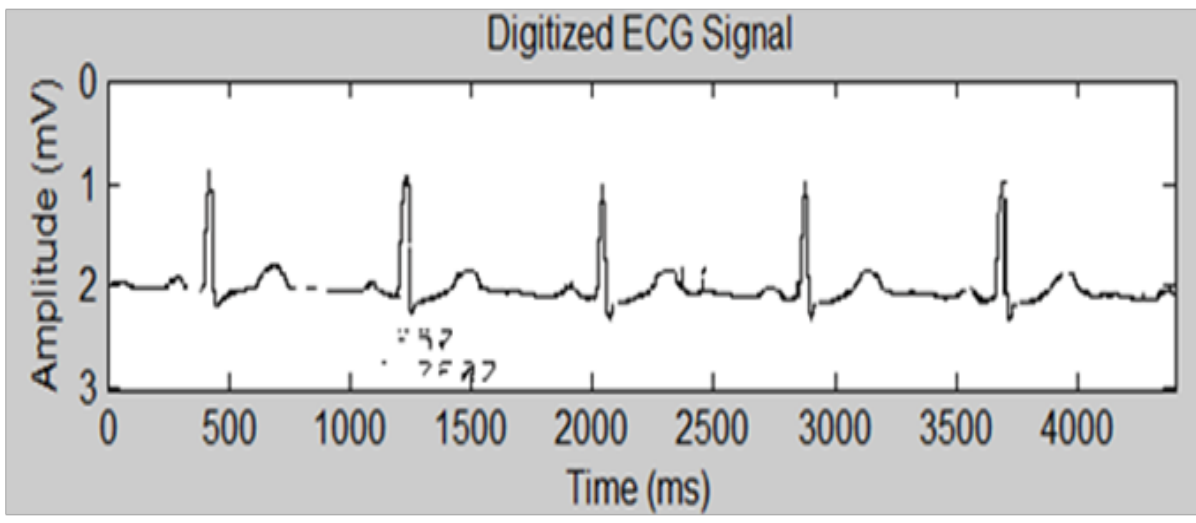

Figure 16 I-D Digitization Signal. 


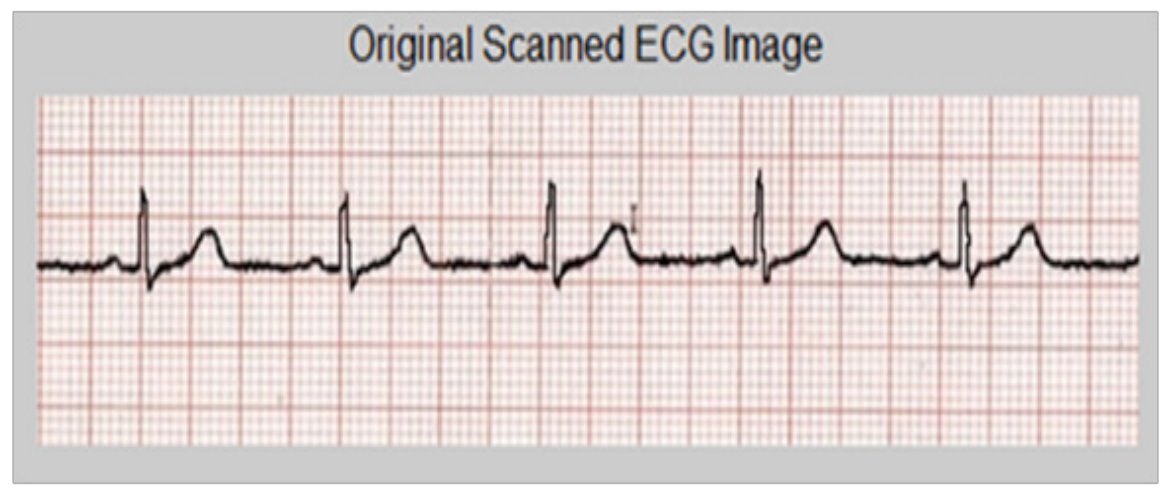

Figure 17 Original Scanned ECG Paper (Without Characters/Small Object).

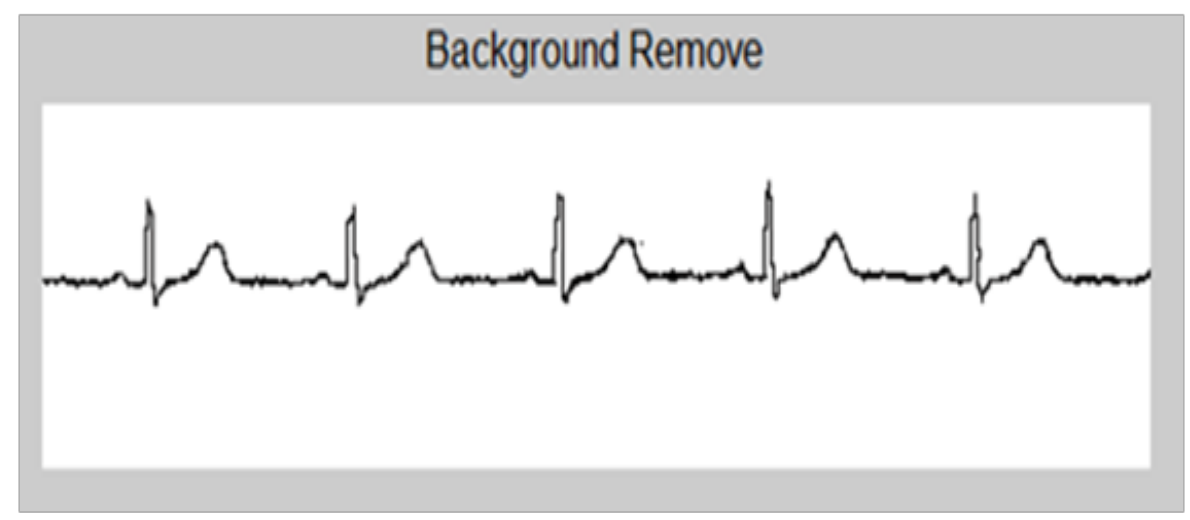

Figure 18 Background Removed Image.

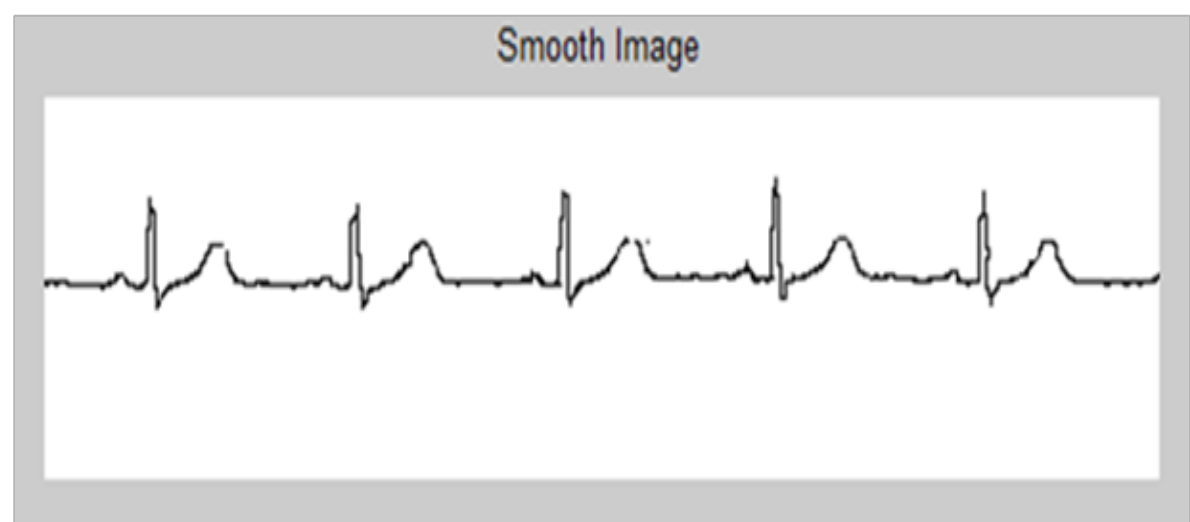

Figure 19 Smoothed ECG Signal.

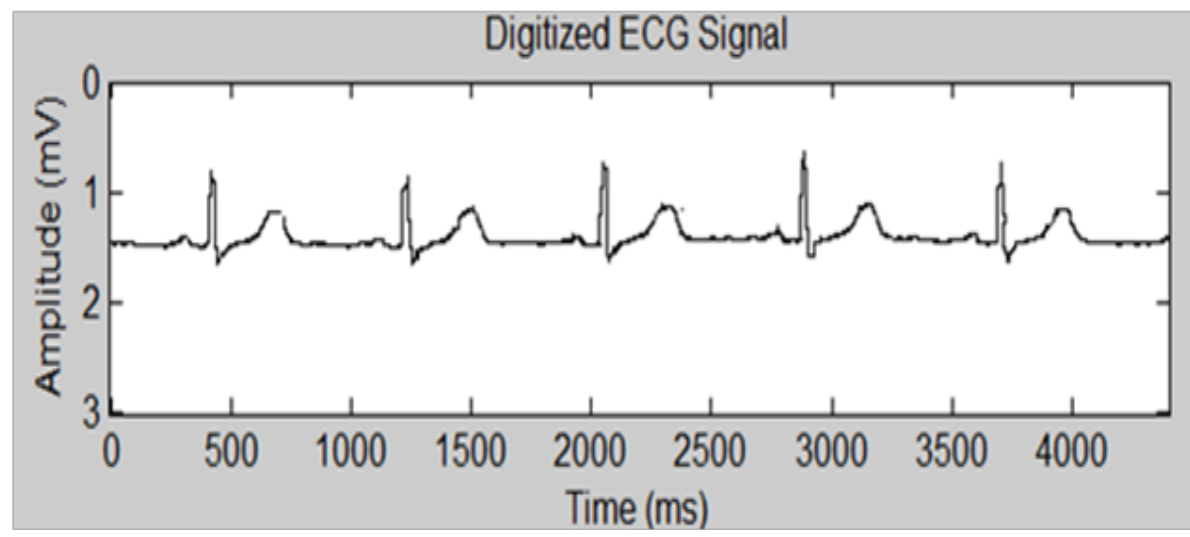

Figure 20 I-D Digitization Signal. 


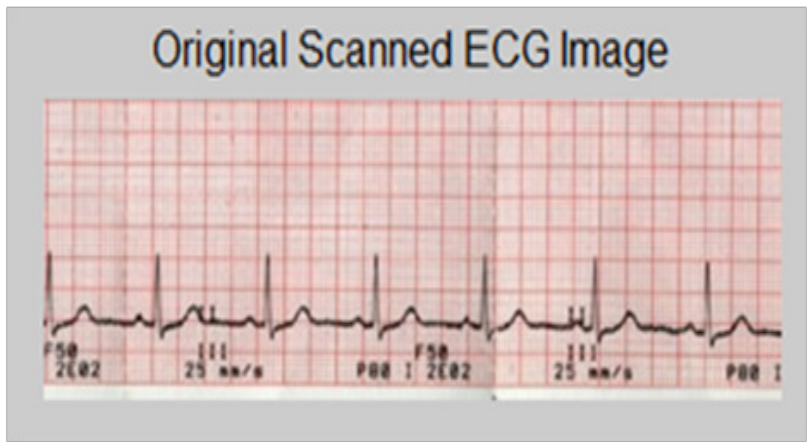

Figure 2 I Scanned ECG Signal (with 300dpi).

\section{Background removing}

This step is applied to remove the background grid of an ECG. Background grid is usually of lighter shade of color than the actual signal waveform. The aim of this step is to cancel the background grid and any other noises from the image. To do so, after the paper based record has been scanned, it is imported into the MATLAB command window. Now the "im2bw ( )" function is used to cancel the background grid. This function converts the image into grayscale first and then using a threshold the image is converted into binaries. It cancels every pixel above that threshold using a threshold value. This procedure is implemented for the image entirely. (Figure 7) shows the enhancement image that yields a better-quality of an image (Figure 8 ) shows the output of background removing it has some printed characters also.

\section{Characters removing}

To remove the characters, region-based segmentation method is used. Firstly the Morphological area opening is used to remove from a binary image all connected components (objects) that have fewer than P pixels. Screenshot result of the morphological (open) method is shown in (Figure 9). In the region-based segmentation step, the background region is divided as segment 1 as shown in the (Figure 11). The signal is divided as segment 2 as shown in the (Figure 12). These two segments are subtracted each other. The segment subtraction result is shown in (Figure 13). In the segment subtraction, ECG signal has the surrounded region. So to get the ECG signal only, background removed image is subtracted from the image after segment subtraction and the output of this step is shown in (Figure 13). This signal is implemented as shown in (Figure 14). In (Figure 15) shows that the ECG signals is smoothed by morphological thicken process because of containing residual effects from the subtraction of the background. Finally, the ECG signal is converted from the waveform image to 1D signal. The $\mathrm{x}$ and $\mathrm{y}$ axis values are calculated based on the input scanned image size. (Figure 16) shows the 1-D digitization signal.

\section{Simulation results with the input image without cha- racter}

Screenshot result of the original scanned ECG image is depicted in (Figure 17). The characters and small object are not included in this figure. Figure 18 shows the output of the background removing. It does not have some printed characters. It can remove all the background grids. Figure 19 shows the smoothed ECG signal and Figure 20 shows the ECG digitization signal. Finally the axis identification is performed in order to adequately interpret the value of the signal obtained.

\section{Simulation results with input image resolution $300 \mathrm{dpi}$}

Scan into images using a commercial A4 scanner with 300dpi. It can be seen that the digitization signal is discontinued. Figure 21 shows the original scanned ECG image with $300 \mathrm{dpi}$. Screenshot result in Figure 22 shows the background removing. It can be seen that the background grid are removed clearly. Although the background grid can be removed, the characters or small object can't be removed with 300dpi. Moreover the ECG waveform image cannot be clear and some wave place has been disappeared. The axis identification can be carried out based on input original scanned ECG image with 300dpi. Figure 23 shows the 1-D digitization signal with 300dpi.

\section{Background Remove}

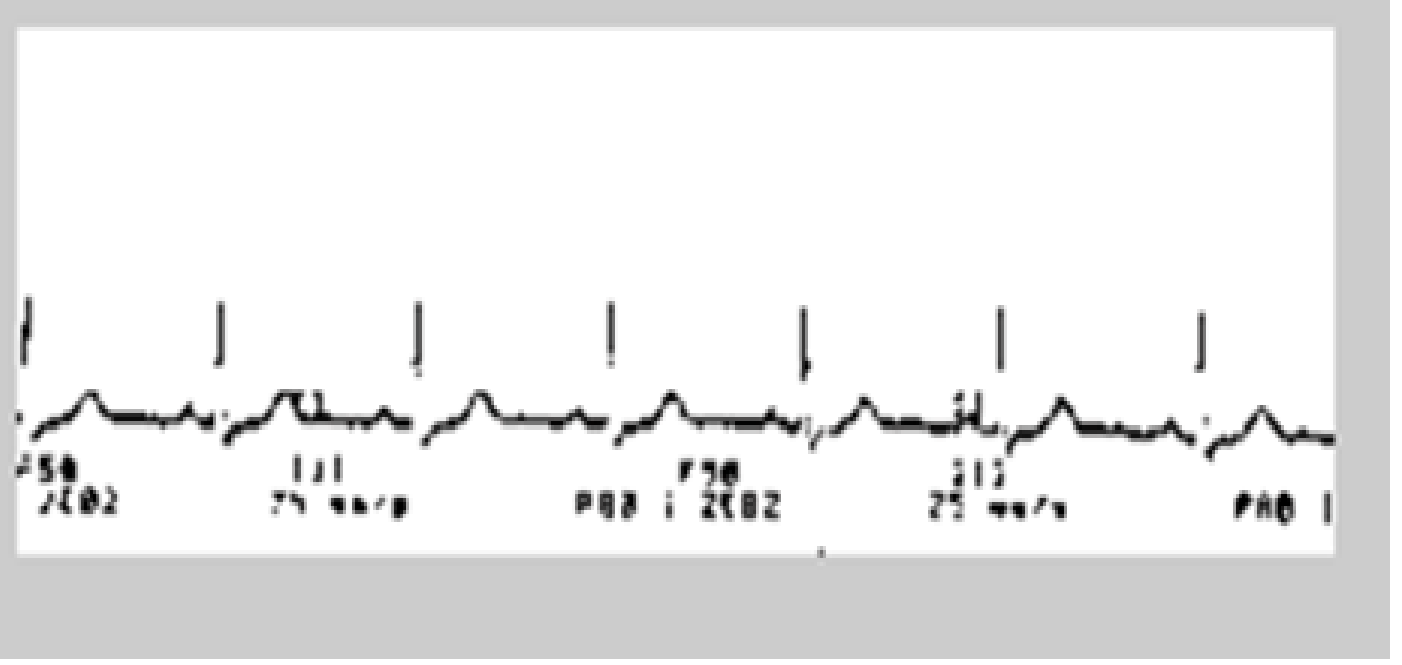

Figure 22 Background Removed (300dpi). 


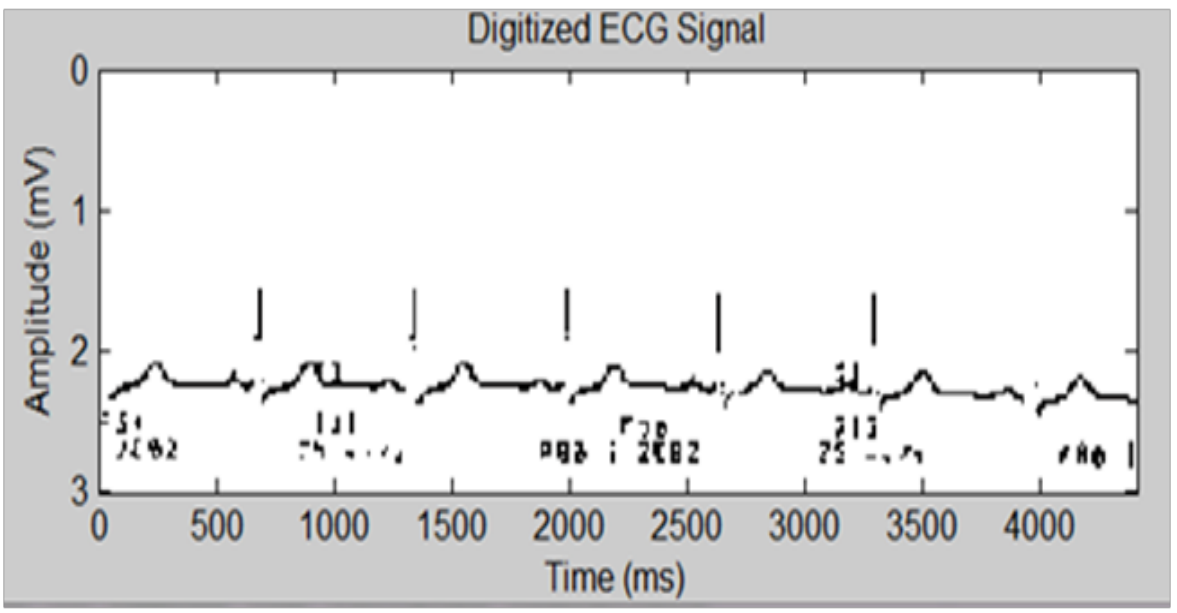

Figure 23 I-D Digitization Signal (300dpi).

\section{Conclusion}

ECG signal digitization algorithm has been developed. The background removing is the main point of this method. The character and small objects removing methods is slightly complicated but it is also needed to absolutely complete the digitization system. In this work, the input image must be scanned with resolution of 600dpi (dots per inch). The background grid and small objects such as characters can be removed exactly. If the image is scanned with resolution of 300 dpi, the background can be removed clearly. But the ECG signal can't be extract correctly. The characters also can't be removed in 300 dpi case. If the scanned ECG image does not have characters or other objects that are not ECG signal, the character and small objects removing step is not needed. Finally the axis identification is performed in order to adequately interpret the value of the signal obtained. An image scanned from a bio-potential paper chart contains uniform or plain background, waveform, text representing amplitude $\mathrm{mV} / \mathrm{mm}$ and recording speed $\mathrm{mm} / \mathrm{sec}$. As shown in the flowchart of the signal extraction and background elimination algorithm, this algorithm mainly depends on binary morphological image operations that will estimate the background. The background then can be subtracted from the original binary image. The morphological operation that will remove the unconnected segment in the binary background free image is conducted. This result image is needed to smooth by using morphological thickness. The waveform now is the only object presented in such image. In this research, the grid is removed from the scanned ECG images by using morphological operation. Region based segmentation can result in isolated pixels that represent printed characters or noise. The presented algorithm can remove any color, grid or black background and character or noise.

\section{Acknowledgements}

None.

\section{Conflict of interest}

Author declares that there is no conflict of interest.

\section{References}

1. Mitchell A, Guyatt G, Singer J, et al. Quality of life in patients with inflammatory bowel disease. J Clin Gastroenterol. 1988;10(3):306-310.

2. Zand A, van Deen WK, Inserra EK, et al. Presenteeism in inflammatory bowel diseases: A hidden problem with significant economic impact. Inflamm Bowel Dis. 2015;21(7):1623-1630.
3. http://www.cdc.gov/ibd/ibd-epidemiology.htm

4. Damle RN, Cherng NB, Flahive JM, et al. Clinical and financial impact of hospital readmissions after colorectal resection: Predictors, outcomes, and costs. Dis Colon Rectum. 2014;57(12):1421-1429.

5. Park KT, Bass D. Inflammatory bowel disease-attributable costs and cost-effective strategies in the united states: a review. Inflamm Bowel Dis. 2011;17(7):1603-1609.

6. Heslop JA, Hammond TG, Santeramo I, et al. Concise review: workshop review: understanding and assessing the risks of stem cell-based therapies. Stem cells translational medicine. 2015;4(4):389-400.

7. Broberger O, Perlmann P. Autoantibodies in human ulcerative colitis. $J$ Exp Med. 1959;110(5):657-674.

8. Wen Z, Fiocchi C. Inflammatory bowel disease: Autoimmune or immune-mediated pathogenesis? Clin Dev Immunol. 2004;11(3-4):195-204.

9. Korsmeyer SJ, Williams RC, Wilson ID, et al. Lymphocytotoxic antibody in inflammatory bowel disease: A family study. The New England journal of medicine. 1975;293:1117-1120.

10. Das KM, Biancone L. Is IBD an autoimmune disorder? Inflammatory Bowel Diseases. 2008;14(Suppl 2):S97-S101.

11. Duerr RH, Targan SR, Landers CJ, et al. Neutrophil cytoplasmic antibodies: A link between primary sclerosing cholangitis and ulcerative colitis. Gastroenterology. 1991;100(5 pt 1):1385-1391.

12. Taniguchi M, Geng X, Glazier KD, et al. Cellular immune response against tropomyosin isoform 5 in ulcerative colitis. Clinical immunology. 2002;101(3):289-295.

13. Ebert EC, Geng X, Bajpai M, et al. Antibody to tropomyosin isoform 5 and complement induce the lysis of colonocytes in ulcerative colitis. Am J Gastroenterol. 2009;104:2996-3003.

14. Halme L, Paavola Sakki P, Turunen U, et al. Family and twin studies in inflammatory bowel disease. World J Gastroenterol. 2006;12(23):36683672 .

15. Ogura $\mathrm{Y}$, Bonen DK, Inohara $\mathrm{N}$, et al. A frameshift mutation in nod2 associated with susceptibility to crohn's disease. Nature. 2001;411(6837):603-606.

16. Prescott NJ, Fisher SA, Franke A, et al. A nonsynonymous snp in ATG1611 predisposes to ileal crohn's disease and is independent of CARD15 and IBD5. Gastroenterology. 2007;132(5):1665-1671.

17. Sewell GW, Marks DJ, Segal AW. AW The immunopathogenesis of crohn's disease: A three-stage model. Curr Opin Immunol. 2009;21(5):506-513. 
18. Diegelmann J, Czamara D, Le Bras E, et al. Intestinal DMBT1 expression is modulated by crohn's disease-associated IL23R variants and by a DMBT1 variant which influences binding of the transcription factors CREB1 and ATF-2. PloS one. 2013;8(11):e77773.

19. Chermesh I, Azriel A, Alter-Koltunoff M, et al. Crohn's disease and SLC11A1 promoter polymorphism. Digestive Diseases and Sciences. 2007;52(7):1632-1635.

20. Dessein R, Chama illard M, Danese S Innate immunity in Crohn's disease: the reverse side of the medal. J Clin Gastroenterol. 2008;42(Suppl 3 Pt 1):S144-S147.

21. Martinez Montiel MP, Munoz Yague MT. Biologic therapies for chronic inflammatory bowel disease. Revista Espanola de Enfermedades Digestivas: Organo Oficial de la Sociedad Espanola de Patologia Digestiva. 2006;98(4):265-291.

22. Hendrickson BA, Gokhale R, Cho JH. Clinical aspects and pathophysiology of inflammatory bowel disease. Clin Microbiol Rev. 2002;15(1):7994.

23. Bielefeldt K, Davis B, Binion DG. Pain and inflammatory bowel disease. Inflamm Bowel Dis. 2009;15(5):778-788.

24. http://www.niddk.nih.gov/health-information/health-topics/digestivediseases/crohns-disease/Pages/facts.aspx.

25. Danese S, Fiocchi C. Ulcerative Colitis. The New England journal of medicine. 2011;365:1713-1725.

26. Varzari A, Deyneko IV, Tudor E, et al. Polymorphisms of glutathione Stransferase and methylenetetrahydrofolate reductase genes in Moldavian patients with ulcerative colitis: Genotype-phenotype correlation. Meta Gene. 2016;7:76-82

27. Botoman VA, Bonner GF, Botoman DA. Management of inflammatory bowel disease. American Family Physician. 1998;57(1):57-68.

28. Thomas A, Lodhia N. Advanced therapy for inflammatory bowel disease: A guide for the primary care physician. Journal of the american board of family medicine. 2014;27(3):411-420.

29. Peyrin Biroulet L, Lemann M. Review article: Remission rates achievable by current therapies for inflammatory bowel disease. Aliment Pharmacol Ther. 2011;33(8):870-879.

30. Allgayer H. Sulfasalazine and 5-ASA compounds. Gastroenterology clinics of North America. 1992;21(3):643-658.

31. Galvez J, Garrido M, Merlos M, et al. Intestinal anti-inflammatory activity of ur-12746, a novel 5-asa conjugate, on acute and chronic experimental colitis in the rat. Br J Pharmacol. 2000;130(8):1949-1959.

32. Brzezinski A, Rankin GB, Seidner DL, et al. Use of old and new oral 5-aminosalicylic acid formulations in inflammatory bowel disease. Cleveland Clinic Journal of Medicine. 1995;62(5):317-323.

33. Bonner GB RW. 5-aminosalicylic acid preparations in the treatment of inflammatory bowel disease. Inflammopharmacology. 1993;2(3):247262.

34. Stenson W. Inflammatory bowel disease. In: T Y, editor. Textbook of gastroenterology. USA: Lippincott; 1995. p. 1748-1805.

35. Gendre JP, Mary JY, Florent C, et al. Oral mesalamine (Pentasa) as maintenance treatment in Crohn's disease: a multicenter placebo-controlled study. The Groupe d'Etudes Thérapeutiques des Affections Inflammatoires Digestives (GETAID). Gastroenterology. 1993;104(2):435-439.

36. Mulder CJ, Tytgat GN, Weterman IT, et al. Double-Blind Comparison of Slow-Release 5-Aminosalicylate and Sulfasalazine in Remission Maintenance in Ulcerative Colitis. Gastroenterology. 1988;95(6):1449-1453.
37. Schroeder KW, Tremaine WJ, Ilstrup DM. Coated oral 5-aminosalicylic acid therapy for mildly to moderately active ulcerative colitis. A randomized study. $N$ Engl J Med. 1987;317(26):1625-1629.

38. Riley SA, Mani V, Goodman MJ, et al. Comparison of delayed-release 5-aminosalicylic acid (mesalazine) and sulfasalazine as maintenance treatment for patients with ulcerative colitis. Gastroenterology. 1988;94(6):1383-1389.

39. Riley SA, Mani V, Goodman MJ, et al. Comparison of delayed release 5 aminosalicylic acid (mesalazine) and sulphasalazine in the treatment of mild to moderate ulcerative colitis relapse. Gut. 1988;29(5):669-674.

40. Prantera C, Pallone F, Brunetti G, et al. Oral 5-aminosalicylic acid (asacol) in the maintenance treatment of crohn's disease. The italian ibd study group. Gastroenterology. 1992;103(2):363-368.

41. Group D-A. Topical 5-aminosalicylic acid versus prednisolone in ulcerative proctosigmoiditis. A randomized, double-blind multicenter trial. Danish 5-asa group. Dig Dis Sci. 1987;32(6):598-602.

42. Spirt MJ. Antibiotics in inflammatory bowel disease: New choices for an old disease. The American Journal of Gastroenterology. 1994;89(7):974 978

43. Hanauer SB, Baert F. Medical therapy of inflammatory bowel disease The Medical clinics of North America. 1994;78(6):1413-1426.

44. Bello C, Goldstein F, Thornton JJ. Alternate-day prednisone treatment and treatment maintenance in crohn's disease. Am J Gastroenterol. 1991;86(4):460-466

45. Vakil N, Sparberg M. Steroid-related osteonecrosis in inflammatory bowel disease. Gastroenterology. 1989;96(1):62-67.

46. Sachar DB. Budesonide for inflammatory bowel disease. It is a magic bullet? N Engl J Med. 1994;331(13):873-874.

47. Hirschfeld S, Clearfield HR. Pharmacologic therapy for inflammatory bowel disease. American Family Physician. 1995;51(8):1971-1975.

48. Sandborn WJ. A review of immune modifier therapy for inflammatory bowel disease: Azathioprine, 6-mercaptopurine, cyclosporine, and methotrexate. Am J Gastroenterol. 1996;91(3):423-433.

49. Pearson DC, May GR, Fick GH, et al. Azathioprine and 6-mercaptopurine in crohn disease. Ann Intern Med. 1995;123(2):132-142.

50. Haber CJ, Meltzer SJ, Present DH, et al. Nature and course of pancreatitis caused by 6-mercaptopurine in the treatment of inflammatory bowel disease. Gastroenterology. 1986;91(4):982-986.

51. Connell WR, Kamm MA, Dickson M, et al. Long-term neoplasia risk after azathioprine treatment in inflammatory bowel disease. Lancet. 1994;343(8908):1249-1252.

52. Botoman VA. Inflammatory bowel disease. In: RB T, editor. Difficult medical management. USA: Saunders; 1991. p. 374-386.

53. Lichtiger S, Present DH, Kornbluth A, et al. Cyclosporine in severe ulcerative colitis refractory to steroid therapy. $N$ Engl J Med. 1994;330(26):1841-1845.

54. Kozarek R, Bedard C, Patterson D, et al. Cyclosporin use in the precolectomy chronic ulcerative colitis patient: A community experience and its relationship to prospective and controlled clinical trials. Pacific northwest gastroenterology society. Am J Gastroenterol. 1995;90(12):2093-2096.

55. Danese S, Fiorino G, Reinisch W. Review article: Causative factors and the clinical management of patients with crohn's disease who lose response to anti-tnf-alpha therapy. Aliment Pharmacol Ther. 2011;34(1):110

56. Danese S. Adalimumab for ulcerative colitis: a little is better than none? Inflamm Bowel Dis. 2012;18(4):793-794. 
57. Sands BE. New drugs on the horizon for IBD. Dig Dis. 2014;32(Supp 1):74-81.

58. Berns M, Hommes DW. Anti-TNF-alpha therapies for the treatment of crohn's disease: The past, present and future. Expert opinion on investigational drugs. 2016;25(2):129-143.

59. Cima RR, Pemberton JH. Surgical management of inflammatory bowel disease. Current treatment options in gastroenterology. 2001;4(3):215225 .

60. Fazio VW, Tjandra JJ, Lavery IC, et al. Long-term follow-up of strictureplasty in crohn's disease. Diseases of the colon and rectum. 1993;36(4):355-361.

61. Tjandra JJ, Fazio VW. Strictureplasty for ileocolic anastomotic strictures in crohn's disease. Dis Colon Rectum. 1993;36(12):1099-1103.

62. Srivastava AS, Shenouda S, Mishra R, et al. Transplanted embryonic stem cells successfully survive, proliferate, and migrate to damaged regions of the mouse brain. Stem cells. 2006;24(7):1689-1694.

63. Irhimeh MR, Cooney J. Management of inflammatory bowel disease using stem cell therapy. Curr Stem Cell Res Ther. 2015;11(1):72-77.

64. Clerici M, Cassinotti A, Onida F, et al. Immunomodulatory effects of unselected haematopoietic stem cells auto transplantation in refractory crohn's disease. Dig Liver Dis. 2011;43(12):946-952.

65. Kashyap A, Forman SJ. Autologous bone marrow transplantation for non-hodgkin's lymphoma resulting in long-term remission of coincidental crohn's disease. British journal of haematology. 1998;103(3):651652 .

66. Da Silva Meirelles L, Chagastelles PC, Nardi NB. Mesenchymal stem cells reside in virtually all post-natal organs and tissues. Journal of cell science. 2006;119(pt 11):2204-2213.

67. Pittenger MF, Mackay AM, Beck SC, et al. Multilineage potential of adult human mesenchymal stem cells. Science. 1999;284(5411):143-147.

68. Kavanagh DP, Kalia N. Hematopoietic stem cell homing to injured tissues. Stem cell reviews. 2011;7(3):672-682.

69. Sallerfors B, Olofsson T. Granulocyte-macrophage colony-stimulating factor (gm-csf) and granulocyte colony-stimulating factor (g-csf) secretion by adherent monocytes measured by quantitative immunoassays European journal of haematology. 1992;49(4):199-207.

70. Lee WY, Park KJ, Cho YB, et al. Autologous adipose tissue-derived stem cells treatment demonstrated favorable and sustainable therapeutic effect for crohn's fistula. Stem cells. 2013;31(11):2575-2581.

71. Iwasaki T. Recent advances in the treatment of graft-versus-host disease. Clin Med Res. 2004;2(4):243-252.

72. Ikehara S. Treatment of autoimmune diseases by hematopoietic stem cell transplantation. Experimental hematology. 2001;29:661-669.

73. Bierman PJ, Sweetenham JW, Loberiza FR, et al. Syngeneic hematopoietic stem-cell transplantation for non-hodgkin's lymphoma: A comparison with allogeneic and autologous transplantation - the lymphoma working committee of the international bone marrow transplant registry and the european group for blood and marrow transplantation. J Clin Oncol. 2003;21(20):3744-3753.

74. Van Deen W. Hematopoietic stem cells: New research: Nova Science. 2012.

75. Lowenthal RM, Cohen ML, Atkinson K, et al. Apparent cure of rheumatoid arthritis by bone marrow transplantation. J Rheumatol. 1993;20(1):137-140.
76. Gratwohl A, Passweg J, Bocelli Tyndall C, et al. Autologous hematopoietic stem cell transplantation for autoimmune diseases. Bone marrow transplant. 2005;35(9):869-879.

77. Martinez Montiel MP, Gomez Gomez GJ, Flores AI. Therapy with stem cells in inflammatory bowel disease. World $J$ Gastroenterol. 2014;20(5):1211-1227.

78. Daikeler T, Hugle T, Farge D, et al. Allogeneic hematopoietic sct for patients with autoimmune diseases. Bone marrow transplant. 2009;44(1):27-33.

79. Farge D, Labopin M, Tyndall A, et al. Autologous hematopoietic stem cell transplantation for autoimmune diseases: An observational study on 12 years' experience from the european group for blood and marrow transplantation working party on autoimmune diseases. Haematologica. 2010;95(2):284-292.

80. Drakos PE, Nagler A. Case of crohn's disease in bone marrow transplantation. Am J Hematol. 1993;43(2):157-158.

81. Lopez Cubero SO, Sullivan KM, McDonald GB. Course of crohn's disease after allogeneic marrow transplantation. Gastroenterology. 1998;114(3):433-440.

82. Swenson E, Theise N. Stem cell therapeutics: Potential in the treatment of inflammatory bowel disease. Clin Exp Gastroenterol. 2010;3:1-10.

83. Burt RK, Craig RM, Milanetti F, et al. Autologous nonmyeloablative hematopoietic stem cell transplantation in patients with severe anti-tnf refractory crohn disease: Long-term follow-up. Blood. 2010;116(26):6123-6132.

84. Cassinotti A, Annaloro C, Ardizzone S, et al. Autologous haematopoietic stem cell transplantation without cd34+ cell selection in refractory crohn's disease. Gut. 2008;57(2):211-217.

85. Oyama Y, Craig RM, Traynor AE, et al. Autologous hematopoietic stem cell transplantation in patients with refractory crohn's disease. Gastroenterology. 2005;128(3):552-563.

86. Hasselblatt P, Drognitz K, Potthoff K, et al. Remission of refractory crohn's disease by high-dose cyclophosphamide and autologous peripheral blood stem cell transplantation. Aliment Pharmacol Ther. 2012;36(8):725-735

87. Hanauer SB. Infliximab: Lifetime use for maintenance is appropriate in crohn's disease. A balancing view: Lifetime channeling of infliximab for crohn's disease. Am J Gastroenterol. 2005;100(7):1438-1439.

88. Hawkey CJ, Allez M, Clark MM, et al. Autologous hematopoetic stem cell transplantation for refractory crohn disease: A randomized clinical trial. Jama. 2015;314(23):2524-2534.

89. Hommes DW, Lacey PN. Stem cells: HSCT for Crohn's disease: Work in progress or a bridge too far? Nat Rev Gastroenterol Hepatol. 2016;13(3):128-130.

90. Friedenstein AJ, Chailakhyan RK, Latsinik NV, et al. Stromal cells responsible for transferring the microenvironment of the hemopoietic tissues. Cloning in vitro and retransplantation in vivo. Transplantation. 1974;17(4):331-340.

91. Sensebe L, Krampera M, Schrezenmeier H, et al. Mesenchymal stem cells for clinical application. Vox sang. 2010;98(2):93-107.

92. Mulder GD, Lee DK, Jeppesen NS. Comprehensive review of the clinical application of autologous mesenchymal stem cells in the treatment of chronic wounds and diabetic bone healing. Int Wound J. 2012;9(6):595600 .

93. Chamberlain G, Fox J, Ashton B, et al. Concise review: Mesenchymal stem cells: Their phenotype, differentiation capacity, immunological features, and potential for homing. Stem cells. 2007;25(11):2739-2749. 
94. Chamberlain G, Smith H, Rainger GE, et al. Mesenchymal stem cells exhibit firm adhesion, crawling, spreading and transmigration across aortic endothelial cells: Effects of chemokines and shear. PloS one. 2011;6(9):e25663.

95. Bianco P, Robey PG, Simmons PJ. Mesenchymal stem cells: Revisiting history, concepts, and assays. Cell stem cell. 2008;2(4):313-319.

96. Boquest AC, Shahdadfar A, Brinchmann JE, et al. Isolation of stromal stem cells from human adipose tissue. Methods Mol Biol. 2006;325:3546.

97. Zhu M, Heydarkhan Hagvall S, Hedrick M, et al. Manual isolation of adipose-derived stem cells from human lipoaspirates. J Vis Exp. 2013;79:e50585.

98. Melief SM, Geutskens SB, Fibbe WE, et al. Multipotent stromal cells skew monocytes towards an anti-inflammatory interleukin-10-producing phenotype by production of interleukin-6. Haematologica. 2013;98(6):888-895.

99. Dominici M, Le Blanc K, Mueller I, et al. Minimal criteria for defining multipotent mesenchymal stromal cells. The international society for cellular therapy position statement. Cytotherapy. 2006;8(4):315-317.

100. Stappenbeck TS, Miyoshi H. The role of stromal stem cells in tissue regeneration and wound repair. Science. 2009;324(5935):1666-1669.

101. Bartholomew A, Sturgeon C, Siatskas M, et al. Mesenchymal stem cells suppress lymphocyte proliferation in vitro and prolong skin graft survival in vivo. Exp Hematol. 2002;30(1):42-48.

102. Le Blanc K, Tammik C, Rosendahl K, et al. HLA expression and immunologic properties of differentiated and undifferentiated mesenchymal stem cells. Experimental hematology. 2003;31(10):890-896.

103. Augello A, Tasso R, Negrini SM, et al. Bone marrow mesenchymal progenitor cells inhibit lymphocyte proliferation by activation of the programmed death 1 pathway. Eur J Immunol. 2005;35(5):1482-1490.

104. Ankrum JA, Ong JF, Karp JM. Mesenchymal stem cells: Immune evasive, not immune privileged. Nature biotechnology. 2014;32:252-260.

105. Schu S, Nosov M, O’Flynn L, et al. Immunogenicity of allogeneic mesenchymal stem cells. Journal of cellular and molecular medicine. 2012;16(9):2094-2103.

106. Nauta AJ, Westerhuis G, Kruisselbrink AB, et al. Donor-derived mesenchymal stem cells are immunogenic in an allogeneic host and stimulate donor graft rejection in a nonmyeloablative setting. Blood. 2006;108(6):2114-2120

107. Lazebnik LB, Lychkova AE, Knyazev OV. Treatment of experimental ulcerative colitis. Bulletin of experimental biology and medicine. 2012;153(6):889-892.

108. Liang J, Zhang H, Wang D, et al. Allogeneic mesenchymal stem cell transplantation in seven patients with refractory inflammatory bowel disease. Gut. 2012;61(3):468-469.

109. Hellers G, Bergstrand O, Ewerth S, et al. Occurrence and outcome after primary treatment of anal fistulae in crohn's disease. Gut 1980;21(6):525-527.

110. Molendijk I, Nuij VJ, Van der Meulen-de Jong AE, et al. Disappointing durable remission rates in complex crohn's disease fistula. Inflamm Bowel Dis. 2014;20(11):2022-2028.

111. De la Portilla F, Alba F, Garcia Olmo D, et al. Expanded allogeneic adipose-derived stem cells (eascs) for the treatment of complex perianal fistula in crohn's disease: results from a multicenter phase I/IIa clinical trial. Int J Colorectal Dis. 2013;28(3):313-323.
112. Ciccocioppo R, Bernardo ME, Sgarella A, et al. Autologous bone marrow-derived mesenchymal stromal cells in the treatment of fistulising crohn's disease. Gut. 2011;60(6):788-798.

113. Molendijk I, Bonsing BA, Roelofs H, et al. Allogeneic bone marrow-derived mesenchymal stromal cells promote healing of refractory perianal fistulas in patients with crohn's disease. Gastroenterology. 2015;149(4):918-927.

114. Onken JGD, Hanson J, Pandak M, et al. Successful outpatient treatment of refractory crohn's disease using adult mesenchymal stem cells. American College of Gastroenterology Conference. 2006.

115. Duijvestein M, Vos AC, Roelofs H, et al. Autologous bone marrow-derived mesenchymal stromal cell treatment for refractory luminal crohn's disease: Results of a phase i study. Gut. 2010;59(12):1662-1669.

116. Forbes GM, Sturm MJ, Leong RW, et al. A phase 2 study of allogeneic mesenchymal stromal cells for luminal crohn's disease refractory to biologic therapy. Clin Gastroenterol Hepatol. 2014;12(1):64-71.

117. Panés J, García-Olmo D, Van Assche G, et al. A phase iii randomised controlled trial of cx601, expanded allogeneic adipose-derived mesenchymal stem cells (easc), for complex perianal fistulas in crohn's disease. Lancet. 2016;10(Suppl 1):388.

118. Tarte K, Gaillard J, Lataillade JJ, et al. Clinical-grade production of human mesenchymal stromal cells: Occurrence of aneuploidy without transformation. Blood. 2010;115(8):1549-1553.

119. Duijvestein M, Molendijk I, Roelofs H, et al. Mesenchymal stromal cell function is not affected by drugs used in the treatment of inflammatory bowel disease. Cytotherapy. 2011;13(9):1066-1073.

120. Gurdon JB. The developmental capacity of nuclei taken from intestinal epithelium cells of feeding tadpoles. J Embryol Exp Morphol. 1962;10:622-640.

121. Takahashi K, Yamanaka S. Induction of pluripotent stem cells from mouse embryonic and adult fibroblast cultures by defined factors. Cell. 2006;126(4):663-676.

122. Spence JR, Mayhew CN, Rankin SA, et al. Directed differentiation of human pluripotent stem cells into intestinal tissue in vitro. Nature. 2011;470(7332):105-109.

123. Haque R, Lei F, Xiong X, et al. Programming of regulatory t cells from pluripotent stem cells and prevention of autoimmunity. J Immunol. 2012;189(3):1228-1236.

124. Wright GP, Notley CA, Xue SA, et al. Adoptive therapy with redirected primary regulatory $\mathrm{t}$ cells results in antigen-specific suppression of arthritis. Proc Natl Acad Sci USA. 2009;106(45):19078-19083.

125. Scalapino KJ, Daikh DI. Suppression of glomerulonephritis in nzb/nzw lupus prone mice by adoptive transfer of ex vivo expanded regulatory $\mathrm{t}$ cells. PloS One. 2009;4(6):e6031.

126. Knoepfler PS. Deconstructing stem cell tumorigenicity: A roadmap to safe regenerative medicine. Stem cells. 2009;27(5):1050-1056.

127. De Girolamo L, Lucarelli E, Alessandri G, et al. Mesenchymal stem/stromal cells: A new "'cells as drugs" paradigm. Efficacy and critical aspects in cell therapy. Curr Pharm Des. 2013;19(13):2459-2473.

128. Panes J, Salas A. Mechanisms underlying the beneficial effects of stem cell therapies for inflammatory bowel diseases. Gut. 2009;58(7):898900 .

129. Scaldaferri F, Vetrano S. Mesenchymal stem cells in IBD: Unmascing their therapeutic mechanisms. Dig Dis Sci. 2015;60(7):1873-1875. 